\title{
Incidence of deep vein thrombosis and leg oedema in patients with strokes
}

\author{
F. B. GIBBERD, S. R. GOULD, AND P. MARKS
}

From the Westminster Hospital, London

SYNOPSIS In a series of 26 patients with strokes 13 had deep vein thrombosis (DVT) in the leg, demonstrated by fibrinogen scanning. In 10 patients the thrombosis was in the paralysed leg but the degree of paralysis was unrelated to the tendency to develop DVT, which usually occurred about the third day. Leg oedema in 10 patients was unrelated to the DVT.

Deep vein thromboses (DVT) are a well-known complication in patients confined to bed. Since the introduction of radioactive fibrinogen scanning techniques more precise diagnosis has been possible and asymptomatic DVT has become well recognised. Patients with acute strokes also often develop oedema of the paralysed limb. The purpose of this study was, firstly, to assess the incidence of oedema and DVT in patients with strokes and, secondly, to assess the aetiological importance of immobilisation of the patients and of paralysis of the limbs in the development of oedema and DVT.

\section{METHODS}

All patients admitted to the Westminster Hospital between October 1973 and April 1974 with acute asymmetrical neurological signs considered to be due to cerebrovascular disease were selected for the study. Patients with transient cerebral ischaemia were excluded.

The patients were assessed for (1) level of consciousness (grade I, conscious; grade II, not always fully conscious); (2) mobility (grade I, walking normally; grade II, walking with limp; grade III, out of bed but not walking; grade IV, confined to bed); (3) weakness of each arm and leg separately (grade I, normal power; grade II, able to lift limb off bed; grade III, able to move but not lift limb; grade IV, unable to move the limb); (4) sensory testing (light touch and pain); and (5) oedema of each arm and leg (grade I, no oedema; grade II, oedema).

Assessments were made within 24 hours of admission and on the third or fourth, seventh,

(Accepted 3 June 1976.) fourteenth, and twenty-eighth days. No patient received anticoagulants. As soon as possible aftefo admission $120 \mathrm{mg}$ potassium iodide was given orally with a further $60 \mathrm{mg}$ every day for two weeks to ${ }^{-\infty}$ reduce the uptake of radioactive iodine by the $\vec{\sim} \vec{N}$ thyroid gland. Each patient was given an intra-- $\mathrm{D} N$ venous injection of ${ }^{125} \mathrm{I}$-fibrinogen with $100 \mu \mathrm{Ci}$ of $\frac{O}{0}$ 음 ${ }^{125}$ I. Counts were made with a portable scintillation 2 counter at the agreed times over the precordium and ${ }^{\sigma}$ over the lower limbs. The counts over each of the limb positions were expressed as a percentage of the pre-0 3 cordial count recorded on the same occasion. This is referred to as the percentage uptake for each limbposition. A persistent difference of more than $15 \%$ between opposite positions or between adjacent points on the same limb was taken to indicate the presence of DVT. Correlations between the various types of data were analysed by the Fisher exact probability test (Siegal, 1956).

\section{RESULTS}

The sensory signs were difficult to assess owing to impaired understanding in some patients and the subjective nature of the examination. Sensory data were therefore excluded from the results. One patient was later discovered to have had her hemiplegia for many weeks and another had a brain tumour. Therefore these two were excluded from the series.

Four patients died and one patient had a pulmonary embolus. Three women died of their cerebrovascular accidents, two of them on the third day (No. 33 and No. 21 who also had a carcinoma of the stomach) and one on the sixth day. One man (No. 16) died on the fifteenth day with a myocardial infarct and a subarachnoid haemorrhage. Three of these four (Nos. 33, 21, 16) had DVT by the third day. 
Table 1 shows the incidence of DVT and oedema. Tables 2 and 3 show the relationship between a positive scan and the clinical findings. Table 2 refers to the legs, but the data for the arms were less complete and are given separately in Table 3 . There was no statistically significant association between DVT and the level of consciousness, power in the weaker leg, the mobility of the patient, and oedema.

Ten of the 26 patients ( $38 \%$ ) had oedema in a leg at some stage. Four patients had oedema at the time of entry to the trial and thus only six (one man and
TABLE 1

INCIDENCE OF DEEP VEIN THROMBOSIS (DVT) AND LEG OEDEMA

\begin{tabular}{lccccc}
\hline & Total & $\begin{array}{c}\text { Mean age } \\
(y r)\end{array}$ & Deaths & Men & Women \\
\hline Total & 26 & 69.8 & 4 & 8 & 18 \\
DVT on scan & 13 & 68.8 & 3 & 4 & $9^{*}$ \\
No DVT & 13 & 70.6 & 1 & 4 & $9^{*}$ \\
Leg oedema & 10 & 70.3 & 3 & 3 & 7 \\
\hline
\end{tabular}

${ }^{*} \mathrm{p}=0.66(\mathrm{NS})$.

TABLE 2

CONSCIOUSNESS, MOBILITY, AND SIGNS IN LEGS RELATED TO DVT

\begin{tabular}{|c|c|c|c|c|c|c|c|c|c|c|}
\hline & \multicolumn{10}{|c|}{ Day of assessment } \\
\hline & \multicolumn{2}{|c|}{1} & \multicolumn{2}{|r|}{$3-4$} & \multicolumn{2}{|r|}{7} & \multicolumn{2}{|r|}{14} & \multicolumn{2}{|r|}{28} \\
\hline $\begin{array}{l}\text { No. patients examined } \\
\text { Conscious (Grade I) } \\
\text { Unconscious (Grade II) }\end{array}$ & \multicolumn{2}{|c|}{$\begin{array}{r}26 \\
18 \\
8\end{array}$} & \multicolumn{2}{|r|}{$\begin{array}{r}25 \\
21 \\
4\end{array}$} & \multicolumn{2}{|c|}{$\begin{array}{r}20 \\
17 \\
3\end{array}$} & \multicolumn{2}{|r|}{$\begin{array}{r}15 \\
14 \\
1\end{array}$} & \multicolumn{2}{|r|}{$\begin{array}{r}11 \\
10 \\
1\end{array}$} \\
\hline $\begin{array}{l}\text { Mobility } \\
\text { Grade I } \\
\text { Grade II } \\
\text { Grade III } \\
\text { Grade IV }\end{array}$ & \multicolumn{2}{|c|}{$\begin{array}{r}2 \\
4 \\
6 \\
14\end{array}$} & \multicolumn{2}{|r|}{$\begin{array}{l}5 \\
5 \\
7 \\
8\end{array}$} & \multicolumn{2}{|r|}{$\begin{array}{l}6 \\
5 \\
4 \\
5\end{array}$} & \multicolumn{2}{|r|}{$\begin{array}{l}4 \\
3 \\
5 \\
3\end{array}$} & \multicolumn{2}{|r|}{$\begin{array}{l}1 \\
3 \\
6 \\
1\end{array}$} \\
\hline & Par.* & on-par. $\dagger$ & Par. & Non-par. & Par. & Non-par. & Par. & Non-par. & Par. & Non-par. \\
\hline $\begin{array}{l}\text { Leg weakness } \\
\text { Grade I } \\
\text { Grade II } \\
\text { Grade III } \\
\text { Grade IV } \\
\text { Leg oedema } \\
\text { No leg oedema } \\
\text { Positive leg scan }\end{array}$ & $\begin{array}{r}9 \\
5 \\
5 \\
7 \\
4 \\
22 \\
-\end{array}$ & $\begin{array}{r}21 \\
1 \\
2 \\
2 \\
26 \\
-\end{array}$ & $\begin{array}{r}12 \\
3 \\
5 \\
5 \\
4 \\
21 \\
8\end{array}$ & $\begin{array}{r}21 \\
1 \\
2 \\
1 \\
2 \\
23 \\
-\end{array}$ & $\begin{array}{r}11 \\
3 \\
5 \\
1 \\
3 \\
17 \\
13\end{array}$ & $\begin{array}{r}16 \\
2 \\
2 \\
3 \\
17 \\
2\end{array}$ & $\begin{array}{r}8 \\
1 \\
5 \\
1 \\
4 \\
11 \\
13\end{array}$ & $\frac{13}{2}$ & $\begin{array}{r}4 \\
2 \\
3 \\
2 \\
3 \\
8 \\
13\end{array}$ & $\begin{array}{r}9 \\
1 \\
1 \\
1 \\
10 \\
2\end{array}$ \\
\hline
\end{tabular}

*Paralysed.

$†$ Non-paralysed.

TABLE 3

SIGNS IN THE ARMS RELATED TO POSITIVE SCAN IN ARMS

\begin{tabular}{|c|c|c|c|c|c|c|c|c|c|c|}
\hline & \multicolumn{10}{|c|}{ Day of assessment } \\
\hline & \multicolumn{2}{|c|}{1} & \multicolumn{2}{|c|}{$3-4$} & \multicolumn{2}{|r|}{7} & \multicolumn{2}{|r|}{14} & \multicolumn{2}{|r|}{28} \\
\hline \multirow[t]{2}{*}{ No. patients examined } & \multicolumn{2}{|c|}{13} & \multicolumn{2}{|r|}{11} & \multicolumn{2}{|r|}{8} & \multicolumn{2}{|r|}{7} & \multicolumn{2}{|r|}{6} \\
\hline & Par.* & on-par. $\dagger$ & Par. & Non-par. & Par. & Non-par. & Par. & Non-par. & Par. & Non-par. \\
\hline \multicolumn{11}{|l|}{ Arm weakness } \\
\hline Grade I & 6 & 12 & 7 & 9 & 6 & 7 & 4 & 6 & 3 & 5 \\
\hline Grade II & 1 & - & - & - & - & - & - & 1 & - & - \\
\hline Grade III & 1 & - & 2 & 1 & 1 & 1 & 1 & - & 1 & 1 \\
\hline Grade IV & 5 & 1 & 2 & 1 & 1 & - & 2 & - & 2 & - \\
\hline Arm oedema & 1 & - & 1 & - & - & - & $\overline{1}$ & - & - & - \\
\hline No arm oedema & 12 & 12 & 10 & 11 & 8 & 8 & 6 & 7 & 6 & 6 \\
\hline Positive arm scan & - & 一 & - & - & - & - & 1 & - & 1 & - \\
\hline
\end{tabular}

*Paralysed.

†Non-paralysed. 
five women) $(23 \%)$ developed oedema while under observation. All 10 of these patients had oedema of the paralysed leg, four also had oedema of the non-paralysed leg, three of the paralysed arm, and none of the non-paralysed arm. Clinical evidence of DVT was not easy to assess apart from the presence of oedema. Three patients with DVT on the scan had pain in the calf but none of these had oedema. There was no relationship between oedema and the level of consciousness. The number of patients was too small for meaningful statistical comparisons between the occurrence of oedema and the degree of limb paralysis or patient mobility.

\section{DISCUSSION}

The neurological assessment, although unsophisticated, did study some of the factors which might influence the development of DVT and oedema. The scan clearly distinguished between cases of DVT and those without DVT. There were no borderline cases. Leg oedema developed in six cases, a similar proportion to the series reported by Exton-Smith and Crockett (1957). None of the patients had massive oedema. When oedema was present in our patients it did not correlate with a positive scan and therefore there is no evidence that oedema was due to a peripheral DVT.

Thirteen patients had DVT in the paralysed leg, and two of these also had DVT in the non-paralysed legs. No patient had DVT in the non-paralysed leg alone. Warlow et al. (1972) also found DVT more commonly in the paralysed leg. One of our patients developed DVT between the seventh and fourteenth day but in all the others it occurred before the seventh day. Although several patients remained immobilised for more than 14 days they developed their DVT only in the earlier days. The highest incidence of onset was at about the third day. Warlow et al. (1972), in their series of patients with cerebrovascular accidents, noted that in more than half the DVT occurred in the first three days of the illness. The age, degree of weakness, or immobility was not related to the incidence of DVT. The results suggest that it is the onset of the illness rather than the continuation of the disability which is the danger.

Paralysis of the muscles can cause local circulatory disturbance (Johnson and Spalding, 1974). An active muscle produces vasodilator substances, and probably reduced flow of blood through the paralysed limbs is due to increased arteriolar tone (Shepherd, 1963). However, these factors would not explain the tendency of DVT to occur within one week of the onset of the paralysis rather than throughout the period of paralysis.
Exton-Smith and Crockett (1957) found oedema, mainly in the upper limbs, in $16 \%$ of patients with hemiplegia. They thought that the oedema was caused by interference with the lymphatic drainage due to decreased muscular activity causing a rise in the protein content of the oedema fluid. Even so, the mechanism for such a high incidence of oedema and DVT in the paralysed limb is uncertain. There could be changes in blood flow or in the walls of the blood vessels. The bed rest itself could not be the cause. Fibrinolytic activity in the blood from the two legs may be different.

The high incidence of DVT raises the question of whether prophylactic low-dose heparin might be advisable. In our series only one patient had a pulmonary embolus, which suggests that DVT is relatively benign. Probably of greater influence in deciding whether to give anticoagulants is the neurological condition which caused the stroke. Anticoagulants are contraindicated in hypertension, cerebral haemorrhage, and large recent cerebral thromboses when bleeding can occur into a softenec infarct. Transient cerebral ischaemia, which is a good? indication for anticoagulants, is unlikely to lead to DVT. In our patients oedema was associated with the paralysed leg and not with a DVT shown on the scan and therefore the oedema is unlikely to be solely due to a DVT. This would imply a cause associated with the paralysis such as the lack of muscular activity rather than a venous stasis. The oedema came on af any time from the start of the illness unlike the DVT, which only took a few days to develop.

In our series the oedema was more common in the legs, whereas Exton-Smith and Crockett (1957) found it more commonly in the arms. Generally our cases of stroke were milder. The mortality was only $15 \%$, whereas in other series it was higher. For example, Warlow et al. (1972) reported a mortality of $37 \%$. Therefore just possibly the oedema is related to the degree of paralysis, but this was not apparent in our patients who had mild symptoms and few complications. In our patients the oedema was often transient and no patient had oedema throughout the whole of the time of study.

\section{ADDENDUM}

Since submitting this paper a series of patients with cerebrovascular disease and deep venous thrombosis after a stroke has been reported (Warlow et al., 1976). The findings in this series were similar to our own.

\section{REFERENCES}

Exton-Smith, A. N., and Crockett, D. J. (1957). Nature of oedema in paralysed limbs of hemiplegic patients. British Medical Journal, 2, 1280-1282. 
Johnson, R. H., and Spalding, J. M. K. (1974). Disorders of the Autonomic Nervous System. Blackwell: Oxford.

Shepherd, J. T. (1963). Physiology of the Circulation in Human Limbs in Health and Disease. Saunders: Philadelphia.

Siegal, S. (1956). Non-Parametric Statistics, p. 96. McGraw Hill: New York.
Warlow, C., Ogston, D., and Douglas, A. S. (1972). Venous thrombosis following strokes. Lancet, 00 , 1305-1306.

Warlow, C., Ogston, D., and Douglas, A. S. (1976). Deep venous thrombosis of the legs after strokes. British Medical Journal, 1, 1178-1183. 